\title{
Smoking habits and carboxyhaemoglobin A cross-sectional study of an urban population of middle-aged men
}

\author{
LARS JANZON, SVEN-ERIK LINDELL, ERIK TRELL, AND PER LARME
} From the Departments of Preventive Medicine, Internal Medicine, Surgery, and Clinical Physiology, University of Lund, Sweden

SUMMARY In this cross-sectional population study we report on the distribution of carboxyhaemoglobin concentrations in the morning, before smoking, in an urban population of 1037 men born in 1931. The median concentration was the same in non-smokers as in ex-smokers: $0.5 \%$. It increased with increasing daily tobacco consumption. But when carboxyhaemoglobin concentrations are measured in reasonably well-standardised circumstances there are large variations between individuals, even in those who smoke equal amounts of tobacco a day. This makes it difficult to predict the concentration in the individual smoker when only his daily tobacco consumption is known. Measurements of carboxyhaemoglobin concentration should be a valuable complement to smoking history to identify the smoker at high risk of cardiovascular disease, to provide an extra argument to make the patient give up the habit, and to reinforce the efforts of those who try to do so.

Smoking is a well-established independent risk factor for cardiovascular disease. ${ }^{1}$ According to results from animal experiments ${ }^{2}$ and cross-sectional population studies, ${ }^{4}$ the damaging effect of tobacco on the vessel wall seems to be related to the amount of carbon monoxide absorbed. The blood concentration of carbon monoxide is dependent on the amount of tobacco smoked a day, the brand of tobacco, inhalation habits, daily exercise habits, and exposure to other environmental sources of carbon monoxide. ${ }^{5}$ Therefore in the individual smoker the blood concentration cannot be predicted with certainty by knowing the number of cigarettes smoked a day. Hence, to identify which smokers are at high risk of cardiovascular diseases, direct measurements of their blood concentrations of carboxyhaemoglobin $(\mathrm{COHb})$ should be a valuable complement to questions about their daily tobacco consumption. To control external sources of variation in $\mathrm{COHb}$, measurements should be made in standardised conditions in terms of physical activity before blood sampling and time since the last cigarette was smoked.

The aim of the present cross-sectional population study was to measure $\mathrm{COHb}$ in middle-aged men in the morning, after a night's sleep and before smoking, and to relate the findings to their smoking habits.

\section{Material and methods}

The sample represented all men attending a screening programme in Malmö who were born in 1931. Smoking habits were assessed by questionnaire. The categories were defined as:

\begin{tabular}{|c|c|}
\hline Non-smoker & $\begin{array}{l}\text { Had not smoked } 1 \mathrm{~g} \text { of tobacco } \\
\text { daily for one year. }\end{array}$ \\
\hline Ex-smoker & $\begin{array}{l}\text { Had not smoked for at least } \\
\text { one month. }\end{array}$ \\
\hline Smoker & $\begin{array}{l}\text { Had smoked at least } 1 \mathrm{~g} \text { of } \\
\text { tobacco daily for at least one } \\
\text { year. }\end{array}$ \\
\hline $\begin{array}{l}\text { Pure } \\
\text { cigarette smoker }\end{array}$ & $\begin{array}{l}\text { (a) }<10 \text { a day (b) } 10-20 \text { a day } \\
\text { (c) }>20 \text { a day. }\end{array}$ \\
\hline $\begin{array}{l}\text { Pure } \\
\text { cigar smoker } \\
\text { Pure }\end{array}$ & Not grouped. \\
\hline $\begin{array}{l}\text { pipe smoker } \\
\text { Mix.' 'moker }\end{array}$ & $\begin{array}{l}\text { (a) } 1 \text { pack a week } \\
\text { (b) }>1 \text { pack a week. } \\
\text { Smoked combinations of pipe, } \\
\text { cigarettes, and/or cigars. }\end{array}$ \\
\hline
\end{tabular}

All the en were asked not to smoke in the morning betc -e the examination. Compliance was checked by questioning. The carbon monoxide in the 
Table Smoking category and carboxyhaemoglobin levels in middle-aged men in Malmö

\begin{tabular}{|c|c|c|c|c|c|c|c|c|c|}
\hline \multirow[b]{2}{*}{ Carboxyhaemoglobin (\%) } & \multirow[b]{2}{*}{$\begin{array}{l}\text { Non- } \\
\text { smokers }\end{array}$} & \multirow[b]{2}{*}{$\begin{array}{l}\text { Ex- } \\
\text { smokers }\end{array}$} & \multicolumn{6}{|c|}{ SMOKING CATEGORY } & \multirow[b]{2}{*}{ All } \\
\hline & & & Under 10 & $10-20$ & Over 20 & $\begin{array}{l}\text { Pipe } \\
\text { smokers }\end{array}$ & $\begin{array}{l}\text { Cigar } \\
\text { smokers }\end{array}$ & $\begin{array}{l}\text { Mixed } \\
\text { smokers }\end{array}$ & \\
\hline $0-0.99$ & 226 & 275 & 14 & 9 & 3 & 7 & 11 & 29 & 574 \\
\hline $1-1.99$ & 4 & 4 & 16 & 77 & 42 & 24 & 4 & 48 & 219 \\
\hline 2-2.99 & - & - & 3 & 50 & 38 & 9 & 3 & 37 & 140 \\
\hline 3-3.99 & - & - & - & 3 & 14 & 1 & 3 & 10 & 31 \\
\hline $4-4.99$ & - & - & - & 1 & 4 & - & - & 2 & 7 \\
\hline $5-5.99$ & - & - & - & 0 & 1 & - & - & - & 1 \\
\hline $6-6.99$ & - & - & - & 1 & 1 & - & - & - & 2 \\
\hline & 230 & 279 & 33 & 141 & 103 & 41 & 21 & 126 & 974 \\
\hline Per cent & $23 \cdot 6$ & $28 \cdot 6$ & 3.4 & 14.5 & $10 \cdot 6$ & $4 \cdot 2$ & $2 \cdot 2$ & 12.9 & 100 \\
\hline Median COHb (\%) & 0.5 & 0.5 & 1.2 & 1.8 & $2 \cdot 2$ & 1.5 & 0.9 & 1.7 & \\
\hline
\end{tabular}

blood was determined as the $\mathrm{COHb}$ concentration according to the method described by Collinson. ${ }^{8}$

The 1037 men in the study comprised $78 \%$ of the total available population in Malmö of men born in 1931. Sixty-three had to be excluded because they had smoked in the morning before the sample was taken. Of the participants, $230(23.6 \%)$ were non-smokers', $279(28.6 \%)$ ex-smokers, 277 (28.5\%) cigarette smokers, $41(4 \cdot 2 \%)$ pipe smokers, 21 (2.2\%) cigar smokers, and $126(12 \cdot 9 \%)$ mixed smokers. The distribution of the $\mathrm{COHb}$ concentrations in the different categories is shown in the Table. The median concentration was the same in non-smokers as in ex-smokers: $0.5 \%$. Neither of these two groups had a concentration higher than $1 \cdot 6 \%$. With increasing cigarette consumption, the median concentration increased from $1.2 \%$ in those who smoked fewer than 10 cigarettes a day to $1.8 \%$ in those smoking 10 to 20 a day and $2 \cdot 2 \%$ in those smoking more than 20 a day. The median value in pipe smokers, $1.5 \%$, was about three times that in ex-smokers and non-smokers. The men classified as pure cigar smokers had concentrations about twice as high as those of ex-smokers and non-smokers.

Among 574 subjects with a $\mathrm{COHb}$ concentration of under $1 \%, 501(87 \%)$ were non-smokers or ex-smokers. Only three of the 103 subjects who smoked more than 20 cigarettes a day had a concentration of under $1 \%$. All those with a concentration of more than $3 \%$ smoked at least $10 \mathrm{~g}$ of tobacco daily. More than half of those who smoked more than $20 \mathrm{~g}$ of tobacco daily had a $\mathrm{COHb}$ value higher than $2 \%$ in the morning and $6 \%$ of them had a morning value higher than $4 \%$.

\section{Discussion}

According to results from animal experiments, ${ }^{23}$ as well as from cross-sectional population studies, ${ }^{4}$ it seems that the damaging effect of tobacco on the vessel wall is related to the blood concentration of carbon monoxide. Hence it would be rational to assess an individual's $\mathrm{COHb}$ concentration to identify those at high risk of cardiovascular disease. There is a large variation in $\mathrm{COHb}$ concentrations between people who smoke equal daily amounts of tobacco, which makes it difficult to predict that their concentrations in the morning will be twice as high as those of non-smokers. Almost $50 \%$ of those who smoked more than 10 cigarettes a day had concentrations four times as high as those of the average non-smoker. Twenty per cent of heavy smokers had $\mathrm{COHb}$ values six times as high as those of non-smokers. Whether a single measurement of the $\mathrm{COHb}$ value really reflects a person's average smoking pattern is, of course, open to question. The reproducibility of the test would depend on how well different external sources of variation were controlled. Measurements taken in the morning, before smoking and after a night's sleep, show smaller variations: in an earlier study of heavy smokers, the mean difference in $\mathrm{COHb}$ values between two samples (with an interval of eight to nine weeks between observations) was less than $1 \%$ (Janzon L, personal communication). Whether the morning value is a better predictor of future arteriosclerotic disease than the value later in the day is a question that has still to be determined in a prospective study. The difference in afternoon and evening values was found by Wald $e t a l^{7}$ to be between $3 \%$ and $4 \%$.

Whether direct measurement of $\mathrm{COHb}$ is a more valid and sensitive test to identify the smoker at high risk of cardiovascular diseases than assessment of daily tobacco consumption by questionnaire is another question that has still to be evaluated in a prospective study. However, in the case-control study by Wald et al, ${ }^{4}$ the concentration of $\mathrm{COHb}$ was found to be better correlated with the prevalence of angina pectoris, intermittent claudication, and previous myocardial infarction than the smoking history. There are now quick, cheap methods of measuring 
carbon monoxide in the expired air and the correlation between carbon monoxide in the expired air and in the blood has been found to be more than $0 \cdot 9 .{ }^{8}$ Direct measurements of individual exposure to different harmful components of tobacco smoke should also be of value in programmes designed to persuade people to stop smoking and in providing information to help those who have already done so. Knowing the magnitude of different tobacco-induced disease $^{1}$ and the benefits of stopping smoking, ${ }^{9}$ we think that direct measurements of expired carbon monoxide should be used as a screening technique and also in most outpatient clinics.

This study was supported by the Swedish Tobacco Company.

Reprints from Dr. Lars Janzon, Department of Preventive Medicine, Malmö General Hospital, S-214 01 Malmö, Sweden.

\section{References}

${ }^{1}$ US Department of Health, Education and Welfare. Smoking and health (4). Cardiovascular diseases. Washington DC: USDHEW, 1979: 7-67.

${ }^{2}$ Astrup P, Kjeldsen K, Wanstrup J. Enhancing influence of carbon monoxide on the development of atheromatosis in cholesterol-fed rabbits. $J$ Atheroscler Res 1967; 7: 343-54.

${ }^{3}$ Thomsen HK. Carbon monoxide-induced atherosclerosis in primates. Atherosclerosis 1974; 20: 233-40.

4 Wald N, Howard S, Smith PG, Kjeldsen K. Association between atherosclerotic diseases and carboxyhaemoglobin levels in tobacco smokers. $\mathrm{Br} \mathrm{Med}$ J 1973; i: 761-5.

${ }^{5}$ Wald N, Howard S, Smith PG, Bailey A. Use of carboxyhaemoglobin levels to predict the development of diseases associated with cigarette smoking. Thorax 1975; 30: 133-40.

- Collison HA, Rodkey FL, O'Neal JD. Determination of carbon monoxide in blood by gas chromatography. Clin Chem 1968; 14: 162.

${ }^{7}$ Wald N, Howard S. Variations of carboxyhaemoglobin levels in smokers. $\mathrm{Br}$ Med J 1975; i: 393.

- Cohen SI, Perkins NM, Ury HK, Goldsmith JR. Carbon monoxide uptake in cigarette smoking. Arch Environ Health 1971; 22: 55-60.

'Schuman LM. The benefits of cessation of smoking. Chest 1971; 59: 421-7. 